\title{
Fabrication, Characterization, and Modeling of an Aluminum Oxide-Gate lon-Sensitive Field-Effect Transistor-Based pH Sensor
}

\author{
Soumendu Sinha ${ }^{1,2}$ (1) $\cdot$ Tapas Pal $^{2,3} \cdot$ Prashant Sharma $^{2} \cdot$ Dheeraj Kharbanda $^{1,2} \cdot$ P. K. Khanna ${ }^{1,2} \cdot$ Amit Tanwar $^{2}$. \\ Rishi Sharma ${ }^{1,2} \cdot$ Ravindra Mukhiya ${ }^{1,2}$
}

Received: 14 April 2021 / Accepted: 9 September 2021 / Published online: 18 October 2021

(c) The Minerals, Metals \& Materials Society 2021

\begin{abstract}
The ion-sensitive field-effect transistor (ISFET) is a popular technology utilized for $\mathrm{pH}$ sensing applications. In this work, we have presented the fabrication, characterization, and electrochemical modeling of an aluminum oxide $\left(\mathrm{Al}_{2} \mathrm{O}_{3}\right)$-gate ISFET-based $\mathrm{pH}$ sensor. The sensor is fabricated using well-established metal-oxide-semiconductor (MOS) unit processes with five steps of photolithography, and the sensing film is patterned using the lift-off process. The $\mathrm{Al}_{2} \mathrm{O}_{3}$ sensing film is deposited over the gate area using pulsed-DC magnetron-assisted reactive sputtering technique in order to improve the sensor performance. The material characterization of sensing film has been done using $\mathrm{x}$-ray diffraction, field-emission scanning electron microscopy, energy-dispersive spectroscopy, and x-ray photoelectron spectroscopy techniques. The sensor has been packaged using thick-film technology and encapsulated by a dam-and-fill approach. The packaged device has been tested in various $\mathrm{pH}$ buffer solutions, and a sensitivity of nearly $42.1 \mathrm{mV} / \mathrm{pH}$ has been achieved. A simulation program with integrated circuit emphasis (SPICE) macromodel of the $\mathrm{Al}_{2} \mathrm{O}_{3}$-gate ISFET is empirically derived from the experimental results, and the extracted electrochemical parameters have been reported. The drift and hysteresis characteristics of the $\mathrm{Al}_{2} \mathrm{O}_{3}$-gate ISFET were also studied, and the obtained drift rates for different $\mathrm{pH}$ buffer solutions of 4,7 , and 10 are $0.136 \mu \mathrm{A} / \mathrm{min}, 0.124 \mu \mathrm{A} /$ min, and $0.108 \mu \mathrm{A} / \mathrm{min}$, respectively. A hysteresis of nearly $5.806 \mu \mathrm{A}$ has been obtained. The developed sensor has high sensitivity along with low drift and hysteresis.
\end{abstract}

Keywords ISFET $\cdot \mathrm{pH}$ sensor $\cdot$ sputtering $\cdot \mathrm{XRD} \cdot \mathrm{XPS} \cdot \mathrm{SPICE}$ macromodel

\section{Introduction}

In recent years, there has been a surge in the demand of handheld point-of-care (POC) electrochemical devices for environmental, biomedical, and food quality monitoring applications. These devices are useful for chemical as well as biosensing applications, owing to several advantages such as small size, fast response and accuracy. ${ }^{1,2}$ Broadly, a chemical/biochemical sensor captures physicochemical signals from an analyte and converts them to a measurable signal,

Soumendu Sinha

soumendu@ceeri.res.in

1 Academy of Scientific and Innovative Research (AcSIR), Ghaziabad 201002, India

2 CSIR - Central Electronics Engineering Research Institute (CEERI), Pilani, Rajasthan 333031, India

3 Department of Nanoscience and Technology, Central University of Jharkhand, Ranchi 835222, India comprising light emission, colorimetric readout, or potential/current modulation. ${ }^{2}$ There are various techniques for signal transduction using optical and non-optical techniques, such as surface plasmon resonance, quartz crystal microbalance, micro-cantilever, and electrochemical techniques. An ion-sensitive field-effect transistor (ISFET) is an electrochemical-based potentiometric technique which has potential to provide real-time and selective detection of chemical and biological analytes, along with the compatibility with the well-established complementary metal-oxide-semiconductor (CMOS) fabrication process. ${ }^{3,4}$ It is a solid-state device, which makes it rugged for the measurement of ion activities in analytes with the aid of a reference electrode, ${ }^{5}$ and it has been widely used for $\mathrm{pH}$ measurements. $\mathrm{pH}$ is one of the most important parameters in agricultural, environmental, biomedical, and potable water studies. ${ }^{6,7}$

The ISFET has attracted much interest due to the feasibility of facile integration with readout circuits. ${ }^{8}$ It is an alternative to the conventional glass membrane electrode-based 
$\mathrm{pH}$ sensors, ${ }^{9}$ where it enables measurements in ultrasmall volumes with fast response. ${ }^{10}$ It is used for chemical as well as biochemical sensing applications by suitable surface functionalization, ${ }^{8,11-14}$ and recently, it has been demonstrated for detecting severe acute respiratory syndrome coronavirus 2 (SARS-CoV-2) virus, which causes COVID-19. ${ }^{15,16}$ For $\mathrm{pH}$ sensing applications, various sensing film materials have been studied in the past, such as aluminum nitride (AlN), silicon dioxide $\left(\mathrm{SiO}_{2}\right)$, silicon nitride $\left(\mathrm{Si}_{3} \mathrm{~N}_{4}\right)$, tantalum pentoxide $\left(\mathrm{Ta}_{2} \mathrm{O}_{5}\right)$, etc. ${ }^{9}, 17$ Several physical and chemical deposition techniques are used to grow the thin films, such as pulsed laser deposition (PLD),${ }^{18}$ magnetron sputtering, ${ }^{19}$ chemical vapor deposition (CVD) ${ }^{20}$ sol-gel technique, ${ }^{21}$ and atomic layer deposition (ALD). ${ }^{22}$ Sputtering is a popular cost-effective process for depositing thin films. Sputtering is carried out by utilizing different variants of power supplies, which include radio frequency (RF), direct current (DC), and pulsed-DC power supply. ${ }^{23,24}$ In order to deposit insulating thin films, the DC reactive sputtering process is not feasible due to the formation of an insulating film on the surface of the target, which results in an operating potential shift due to poisoning of the target, which is undesirable. ${ }^{25,26}$ Although these problems have been resolved by using RF power supplies, they provide low deposition rates and require tedious process optimization to obtain desired network matching required for an efficient sputtering process. ${ }^{25}$ Pulsed-DC sputtering is a popular cost-effective technique which addresses these issues for depositing thin films. ${ }^{27}$ Pulsed-DC sputtering facilitates easier process optimization because it does not require costly and complex matching networks required for the RF sputtering process, which makes it more widely adopted in the industrial production units worldwide. ${ }^{28}$ Moreover, when sputtering is assisted by a magnetron, the sputtering efficiency increases, leading to higher film growth rate, and the obtained film quality is better than the films grown under similar process conditions, viz., operating pressure and substrate temperature, in comparison to conventional sputtering techniques, as described by the structure zone model. ${ }^{29-31}$

In this work, we have deposited aluminum oxide $\left(\mathrm{Al}_{2} \mathrm{O}_{3}\right)$ thin film using pulsed-DC magnetron-assisted reactive sputtering technique. Aluminum oxide is amphoteric in nature and has a wide bandgap, ${ }^{32,33}$ with excellent mechanical, optical, and electrical properties..$^{34,35}$ It is a robust material which is chemically stable and wear resistant, which enables it to be used for widespread applications, such as abrasive materials, electrical insulators, cutting tools, etc. ${ }^{36-38}$ Moreover, it is a biocompatible material, which allows it to be used for dentistry and orthopedic applications. ${ }^{36,39,40} \mathrm{Al}_{2} \mathrm{O}_{3}$ material has also been studied for $\mathrm{pH}$ sensing applications, where it has been demonstrated to have very good hysteresis characteristics and low long-term drift, which makes it a promising material to be used as a sensing film of an
ISFET. ${ }^{41,42}$ We have fabricated an $\mathrm{Al}_{2} \mathrm{O}_{3}$-gate ISFET $\mathrm{pH}$ sensor using the self-aligned process, with the sensing film patterned using a lift-off process. The experimental results are empirically validated through Simulation Program with Integrated Circuit Emphasis (SPICE) macromodeling, ${ }^{43}$ and the extracted electrochemical parameters have been reported.

We obtained a high sensitivity and low drift using $\mathrm{Al}_{2} \mathrm{O}_{3}$ as a sensing film of the ISFET. To the best of our knowledge, this is the first time $\mathrm{Al}_{2} \mathrm{O}_{3}$ sensing film grown using costeffective pulsed-DC magnetron-assisted reactive sputtering approach has been demonstrated for ISFET $\mathrm{pH}$ sensor applications. In the past, $\mathrm{Al}_{2} \mathrm{O}_{3}$ thin films have been deposited using $\mathrm{CVD}^{44-47}$ and $\mathrm{ALD}^{48-50}$ processes in order to be used as sensing films for ISFET $\mathrm{pH}$ sensor applications. Both CVD and ALD processes have inherent disadvantages in comparison to sputtering processes, although the quality of deposited films are good. CVD processes involve high temperatures for the deposition of $\mathrm{Al}_{2} \mathrm{O}_{3}$ thin films. The hightemperature processing is not acceptable in the presence of metallic layers such as aluminum in the device structure, which makes the CVD incompatible with the developed self-aligned process in this work, where the sensing film is deposited and patterned as the last step by using the lift-off process. Moreover, CVD requires specialized precursors, which increases the process complexity. In addition, the precursors and the by-products are toxic and pyrophoric, which is undesirable for commercial production of ISFET $\mathrm{pH}$ sensors. ${ }^{24}$ ALD processes for deposition of thin films are very costly due to the requirement of high-grade precursors which are toxic and pyrophoric. They also provide a very slow growth rate, which is its major limitation. Moreover, it involves tedious process optimization and is commercially not viable due to low throughput. ${ }^{51,52}$ In contrast, sputtering is a simpler, low-temperature, cost-effective, and environmentally friendly process for thin-film deposition, suitable for commercial production of ISFET $\mathrm{pH}$ sensors.

The paper is further organized as follows: Section "ISFET Principles and Theory" discusses the theory of ISFET sensor operation and the site binding model. Section "Material and Methods" describes the process optimization of sensing film deposition and fabrication process of the sensor. Results and discussion have been presented in the section "Results and Discussion," which consists of material and device characterization results. Finally, conclusions are presented in the section "Conclusions."

\section{ISFET Principles and Theory}

ISFET is a FET-based chemical sensor popularly used for $\mathrm{pH}$ sensing applications. Unlike a metal-oxide-semiconductor field-effect transistor (MOSFET), the gate electrode is absent in an ISFET, and the gate region is left exposed during device 
packaging to allow interaction of the gate oxide with analyte solutions. The sensor is immersed in the analyte along with a reference electrode, where the solution comes in contact with the exposed gate region ${ }^{10,17,53}$ as shown in Fig. 1. A reference potential is applied to the solution with the aid of a reference electrode. ${ }^{9}$ When immersed in analyte, due to the formation of charges at the insulator-electrolyte interface, the channel conductivity is modulated, leading to accumulation or depletion of charges near the oxide-silicon interface, which causes a shift in the threshold voltage $\left(V_{\mathrm{TH}}\right)$ of the transistor. ${ }^{43,54,55}$ The threshold voltage of an ISFET depends upon the electrochemical parameters and surface potential at the solid-electrolyte interfaces; i.e. between the analyte and the gate oxide on one side, and the analyte and the reference electrode on the other side. ${ }^{9,56}$

The expression for current between drain and source of the ISFET in the unsaturated region is given by: ${ }^{43}$

$I_{\mathrm{DS}}=K_{n}\left[\left(V_{\mathrm{GS}}-V_{T H}\right)-\frac{V_{\mathrm{DS}}}{2}\right] V_{\mathrm{DS}}$

where $I_{D S}$ is the drain current; $K_{n}$ is the transconductance parameter; $V_{\mathrm{GS}}$ is the gate source voltage; $V_{\mathrm{TH}}$ is the threshold voltage; and $V_{\mathrm{DS}}$ is the drain source voltage.

The threshold voltage expression for the ISFET is given as: ${ }^{10}$

$$
\begin{aligned}
V_{\mathrm{TH}}= & E_{\mathrm{ref}}-\Psi_{0}+X^{s o l}-\frac{\phi_{S i}}{q} \\
& -\frac{Q_{\mathrm{SS}}+Q_{O X}+Q_{B}}{C_{\mathrm{OX}}}+2 \psi_{F}
\end{aligned}
$$

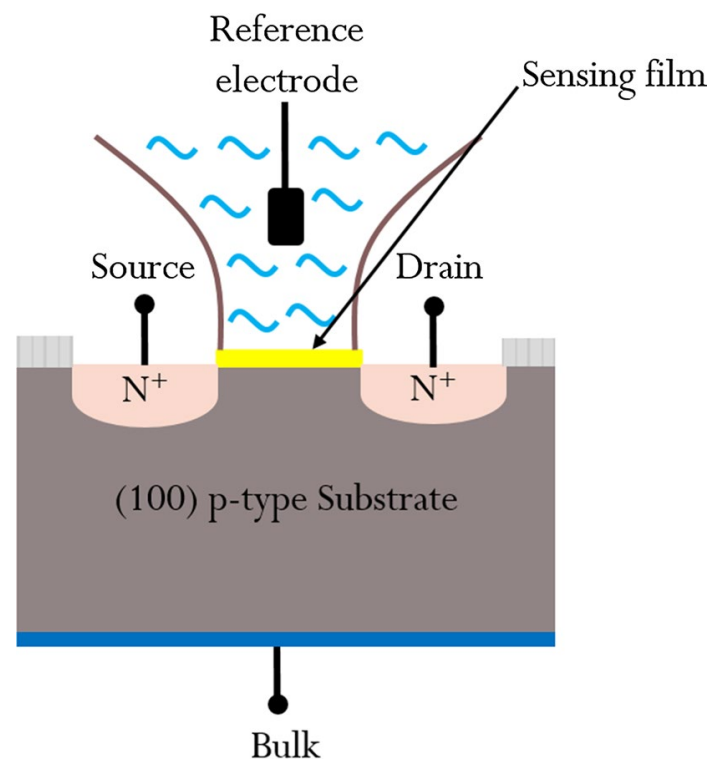

Fig. 1 Cross-sectional schematic of an ISFET (adapted with permission from Ref. 17, copyright 2019, Springer Nature). where $E_{\text {ref }}$ is the reference electrode potential; $\Psi_{0}$ is the surface potential at the insulator-electrolyte interface; $X^{\text {sol }}$ is the surface dipole potential of the solution; $\phi_{S i}$ is the work function of $\mathrm{Si}$ (substrate); $q$ is the elementary charge; $Q_{S S}$ is the accumulated charge at the $\mathrm{O}_{2} / \mathrm{Si}$ interface; $Q_{O X}$ is the accumulated charge in the oxide; $Q_{B}$ is the depletion charge in the silicon; $C_{O X}$ is the oxide capacity per unit area; and $\psi_{F}$ is the Fermi potential. Here, $\Psi_{0}$ is the only parameter which depends on the $\mathrm{pH}$ of the solution. The surface potential of the electrolyte/insulator interface can be calculated using the site-binding model, ${ }^{57}$ and which was further elucidated by Bousse et al. and Fung et al. to characterize ISFETs with various gate insulators. ${ }^{58,59}$ Figure 2 shows a schematic of the surface sites of $\mathrm{Al}_{2} \mathrm{O}_{3}$ sensing film, where the surface of sensing film has amphoteric sites capable of accepting or donating protons, and where $\mathrm{Al}$ represents the metal. The resultant surface charge density depends upon the $\mathrm{pH}$ of the analyte and the electrochemical parameters of the sensing film, consisting of dissociation constants and the intrinsic buffer capacity. ${ }^{13}$ Thus, the surface sites have three different forms which are negatively charged $\left(\mathrm{AlO}^{-}\right)$, positively charged $\left(\mathrm{AlOH}_{2}^{+}\right)$, and neutral sites $(\mathrm{AlOH})$.

\section{SPICE Macromodel Formulation}

The ISFET device is considered as a combination of two stages, i.e. an electrochemical stage, which contains the electrolyte/insulator interface, and an electronic stage, which consists of a MOSFET. Let $\sigma_{\text {diff }}, \sigma_{0}$, and $\sigma_{s}$ represent

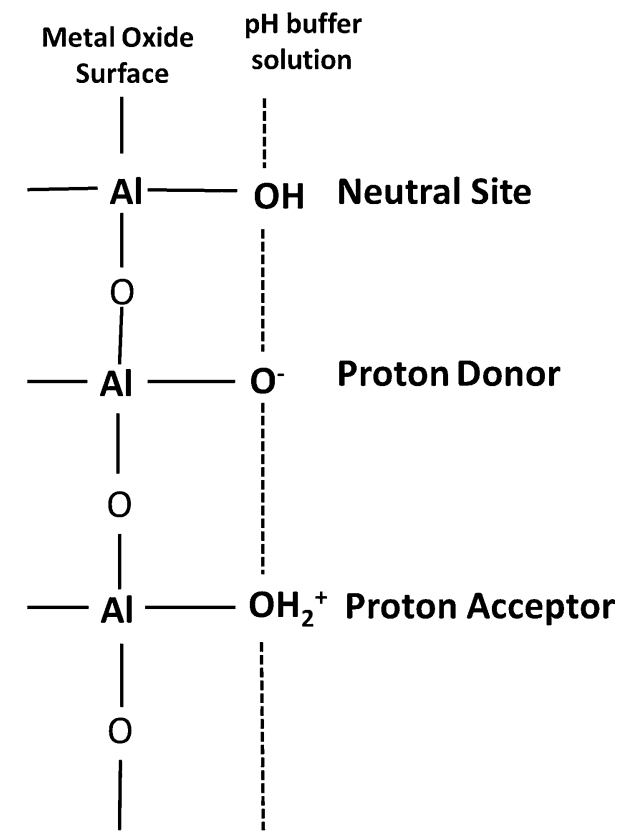

Fig. 2 Schematic diagram of the surface sites according to site-binding model. 
the charge densities in the diffuse layer, at the electrolyte/ insulator interface, and in the semiconductor, respectively. By using the condition of charge neutrality of the structure:

$\sigma_{\text {diff }}+\sigma_{0}+\sigma_{s}=0$

Assuming $\sigma_{s}$ to be much smaller than $\sigma_{\text {diff }}$ and $\sigma_{0}$, and considering it to be constant with $\mathrm{pH},{ }^{58}$ Eq. 3 reduces to:

$\sigma_{\text {diff }}+\sigma_{0}=0$

Using the electrical double-layer theory and site-binding model, ${ }^{57,59-61}$ we obtain

$\sigma_{\text {diff }}=\sqrt{8 \epsilon_{w} \epsilon_{0} k T C_{b}} \sinh \left(\frac{z q \psi_{r d}}{2 k T}\right)$

where $\psi_{r d}$ is the potential across the diffuse layer; $\epsilon_{w}$ and $\epsilon_{0}$ are the permittivity of the electrolyte and free space, respectively; $T$ is the temperature (kelvin); $k$ is the Boltzmann constant; $C_{b}$ is the concentration of bulk solution (no./lit); $z$ is the valence of the ion; and $q$ is the elementary charge.

$\sigma_{o}=q N_{s}\left(\frac{a_{H_{s}^{+}}^{2}-K_{a} K_{b}}{K_{a} K_{b}+K_{b} a_{H_{s}^{+}}+a_{H_{s}^{+}}^{2}}\right)$

where $N_{s}$ is the surface site density; $K_{a}$ and $K_{b}$ are the intrinsic dissociation constants for deprotonation and protonation reactions, respectively; and $\mathrm{a}_{\mathrm{H}_{\mathrm{S}}^{+}}$is the proton activity near the electrolyte/insulator interface. Figure 3 shows a potential diagram for the ISFET, depicting the potential across the diffuse layer $\left(\psi_{r d}\right)$ and the surface potential $\left(\psi_{o}\right)$.

Equation 4 can also be written as :

$\sigma_{\text {diff }}=-\sigma_{0}=-C_{D i f f} \cdot \psi_{0}$

where $C_{\text {Diff }}$ represents the double-layer capacitance, which is a series combination of diffuse layer capacitance and Stern capacitance. As stated by the

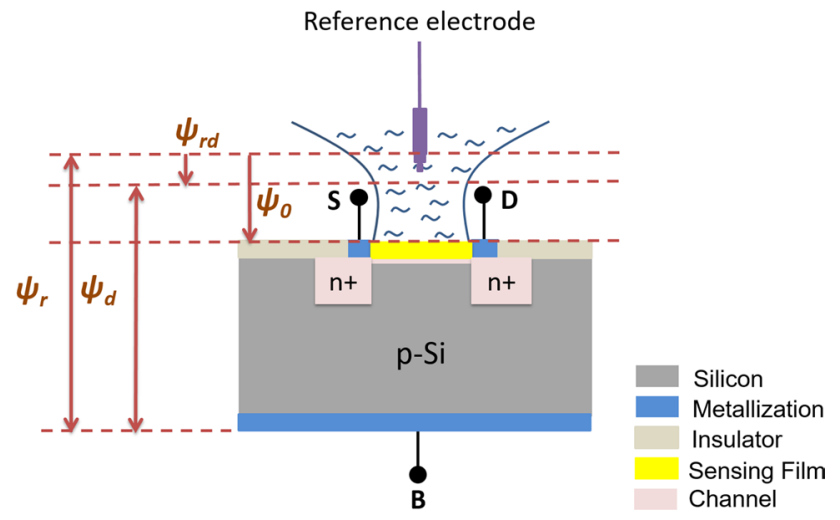

Fig. 3 Schematic of ISFET showing the potential diagram (adapted with permission from Ref. 62, copyright 2000, Elsevier).
Gouy-Chapman-Stern-Graham model, an electrical double layer is formed in the electrolyte near the electrolyte/insulator interface due to the presence of surface charges, consisting of an inner Helmholtz plane (IHP) and outer Helmholtz plane (OHP), which are the locus of centers of adsorbed ions and solvated ions, respectively; and a diffuse layer is present away from the OHP towards the bulk of the electrolyte. ${ }^{9,17,63}$ This leads to the formation of Stern capacitance $\left(C_{\mathrm{Helm}}\right)$ and diffuse layer capacitance $\left(C_{\text {Gouy }}\right)$ in the electrolyte, ${ }^{58,62}$ whose expressions are given as follows:

$C_{\mathrm{Helm}}=\frac{\epsilon_{\mathrm{IHP}} \epsilon_{\mathrm{OHP}}}{\epsilon_{\mathrm{IHP}} d_{\mathrm{OHP}}+\epsilon_{\mathrm{OHP}} d_{\mathrm{IHP}}} W L$

$C_{\text {Gouy }}=\frac{\sqrt{8 \epsilon_{w} \epsilon_{o} k T C_{b}}}{2 V_{T}}$

where $\epsilon_{\mathrm{OHP}}$ and $\epsilon_{\mathrm{IHP}}$ are the relative permittivity of the OHP and IHP, respectively; $d_{\mathrm{OHP}}$ and $d_{\mathrm{IHP}}$ are the locus of the center of planes of the OHP and IHP, respectively; $k$ is the Boltzmann constant; $W$ and $L$ are the gate width and gate length of the ISFET sensor, respectively; $\epsilon_{w}$ is the dielectric constant of water; $\epsilon_{0}$ is the permittivity of free space; $V_{T}$ is the thermal voltage; and $C_{b}$ is the concentration of the electrolyte. Thus, the expression for $C_{\text {Diff }}$ is given by:

$C_{\text {Diff }}=\frac{C_{\text {Helm }} C_{\text {Gouy }}}{C_{\text {Helm }}+C_{\text {Gouy }}}$

By using 6,7, and 10, we obtain the potential of the electrolyte/insulator interface as:

$\psi_{0}=\frac{q N_{s}}{C_{\text {Diff }}}\left[\frac{a_{H_{s}^{+}}^{2}-K_{a} K_{b}}{K_{a} K_{b}+K_{b} a_{H_{s}^{+}}+a_{H_{s}^{+}}^{2}}\right]$

The SPICE macromodel is simulated using the electrical equivalent model of coupled electrochemical and electronic stages as discussed in the section "SPICE Macromodel Formulation," 17 where a new subcircuit block is defined. The subcircuit block consists of five terminals, viz., source, drain, bulk, an independent $\mathrm{pH}$ input terminal, and a reference electrode. ${ }^{43}$ The electrochemical parameters of the ISFET are empirically extracted from the experimental results by parametric sweep, and the closely fitted results are reported. The electrical device parameters are extracted using MOSFET test structures fabricated alongside ISFET devices on the same wafer and validated using process simulations performed in Silvaco ${ }^{\circledR}$ Athena ${ }^{\mathrm{TM}}$. The device parameters of fabricated ISFET devices are listed in Table I. 
Table I ISFET device parameter values.

\begin{tabular}{ll}
\hline Parameters & Value \\
\hline Width & $500 \mu \mathrm{m}$ \\
Length & $20 \mu \mathrm{m}$ \\
Gate oxide thickness & $50 \mathrm{~nm}$ \\
Aluminum oxide thickness & $100 \mathrm{~nm}$ \\
Sheet resistance (source and drain) & $1.74 \Omega / \square$ \\
Substrate doping & $2 \mathrm{E}+15 \mathrm{~cm}^{-3}$ \\
Junction depth & $1.2 \mu \mathrm{m}$ \\
Lateral diffusion & $0.96 \mu \mathrm{m}$ \\
\hline
\end{tabular}

\section{Material and Methods}

ISFET-based $\mathrm{pH}$ sensors have the advantage of being batch fabricated using well-established MOS unit processes, which significantly reduces the production cost of these sensors. Moreover, the fabrication process and device design is simple, which reduces elaborate unit process optimization requirements. In this work, $\mathrm{Al}_{2} \mathrm{O}_{3}$-gate ISFET-based $\mathrm{pH}$ sensors were fabricated using the self-aligned process. The self-aligned process involves five levels of lithography, where the final step of lithography step involves a lift-off process to pattern the $\mathrm{Al}_{2} \mathrm{O}_{3}$ thin film. The sensing film was deposited using pulsed-DC magnetron-assisted reactive sputtering technique. The sensing film material was characterized using $\mathrm{x}$-ray diffraction (XRD), field-emission scanning electron microscopy (FESEM), energy-dispersive spectroscopy (EDS), and x-ray photoelectron spectroscopy (XPS) techniques.

\section{Process Optimization for the Deposition of Sensing Film}

Pulsed-DC magnetron-assisted reactive sputtering technique has been used for the deposition of $\mathrm{Al}_{2} \mathrm{O}_{3}$ thin film. The target potential switches in the frequency range of $10-350 \mathrm{kHz}$ from negative potential to either positive or ground potential in a pulsed-DC power supply. ${ }^{30}$ This is helpful in avoiding target poisoning. During the negative potential cycle, a thin layer of dielectric is formed over the target, which reduces the sputtering efficiency of bombarding ions. Moreover, the ions begin to charge the dielectric, which may lead to dielectric breakdown over the target surface, leading to melting and ejection of droplets of target material, which degrades the quality of thin film deposited over the substrate. However, when the potential switches to a positive value, the secondary electrons in the plasma get attracted towards the target and neutralize the charged dielectric, and during the next negative cycle, the ions bombard the target and remove the dielectric layer formed on target surface. Thus, the pulsed-DC power supply enables target cleaning during the reverse pulse duration. The film quality, deposition rate, and stoichiometry of the deposited film are influenced by several process parameters, which include operating power, ${ }^{64}$ substrate temperature, ${ }^{31}$ target-to-substrate distance, ${ }^{65}$ operating frequency, ${ }^{66}$ and reverse time. ${ }^{66}$ The process parameters are experimentally optimized to obtain the desired stoichiometry, film quality, and thickness. It has been reported that a higher operating frequency, longer reverse time, and higher deposition temperature is desirable to obtain good quality of thin-film growth. ${ }^{17,31}$

The deposition process for $\mathrm{Al}_{2} \mathrm{O}_{3}$ sensing film has been developed using the TFSP- $840^{\circledR}$ sputtering system (VST, Israel) using a bipolar pulsed-DC power source. A number of iterations were carried out for optimizing the $\mathrm{Al}_{2} \mathrm{O}_{3}$ film deposition process. A number of combinations of pulsed-DC power in the range of $200 \mathrm{~W}$ to $500 \mathrm{~W}$ were used with varying flow rates of argon and oxygen gases for the deposition of the $\mathrm{Al}_{2} \mathrm{O}_{3}$ thin film. We used a $99.99 \%$ pure aluminum target for the thin-film deposition. Initially, a base pressure of $1.25 \times 10^{-7} \mathrm{kPa}$ was achieved in the process chamber of the sputtering system. After achieving the base pressure, the substrate was maintained at $100^{\circ} \mathrm{C}$ during the deposition process. A process pressure of nearly $0.82 \mathrm{~Pa}$ was maintained by controlling the gas flow of argon (Ar) and oxygen $\left(\mathrm{O}_{2}\right)$ in the ratio $4: 1$. On achieving stable chamber pressure, a $350-\mathrm{W}$ pulsed-DC power was applied to the target with an operating frequency of $100 \mathrm{kHz}$ and a reverse time of $3 \mu \mathrm{s}$. On the stabilization of applied power, the shutter in front of the aluminum target was opened to begin the deposition process. The substrate holder was rotated at $20 \mathrm{RPM}$ at a distance of $60 \mathrm{~mm}$ the target to achieve uniform thin-film deposition. The deposition process was carried out for 10 min to achieve nearly 100 -nm thickness of $\mathrm{Al}_{2} \mathrm{O}_{3}$ sensing film. Table II lists the optimized parameters used for the deposition of the sensing film.

\section{ISFET Device Fabrication}

The fabrication process of an ISFET is similar to a MOSFET; however, the fundamental difference is the absence of gate electrode in an ISFET. In addition to this, a sensing film is stacked on top of the gate oxide to enhance the sensing performance. Moreover, the encapsulation and packaging process of an ISFET is different from a MOSFET because the gate region having sensing film must be exposed to the electrolyte to allow the formation of an electrolyte/insulator interface in order to measure the $\mathrm{pH}$ sensitivity.

Figure 4 shows the fabrication process of an ISFET sensor. We use a $p$-type $<100>$ silicon wafer with resistivity of 1-10 $\Omega$-cm for device fabrication (Fig. 4a). Firstly, using thermal oxidation method, a $1-\mu \mathrm{m}$-thick oxide layer was grown on both sides of the wafer using a wet oxidation process (Fig. 4b). Next, the source and drain regions 
Table II Process parameters for $\mathrm{Al}_{2} \mathrm{O}_{3}$ thin-film deposition by reactive sputtering technique.

\begin{tabular}{ll}
\hline Parameter & Value \\
\hline Operating power & $350 \mathrm{~W}$ \\
Base pressure & $1.25 \times 10^{-7} \mathrm{kPa}$ \\
Operating pressure & $0.82 \mathrm{~Pa}$ \\
Ar flow rate & $4.8 \mathrm{sccm}$ \\
$\mathrm{O}_{2}$ flow rate & $1.2 \mathrm{sccm}$ \\
Operating frequency & $100 \mathrm{kHz}$ \\
Reverse voltage & $10 \%$ of pulse on voltage \\
Reverse time & $3 \mu \mathrm{s}$ \\
Substrate temperature & $100^{\circ} \mathrm{C}$ \\
Time taken for deposition & $10 \mathrm{~min}$ \\
Target-to-substrate distance & $6 \mathrm{~cm}$ \\
\hline
\end{tabular}

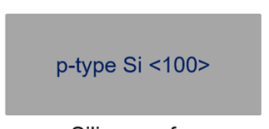

Silicon wafer

(a)

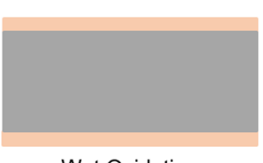

Wet Oxidation

(b)

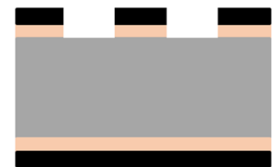

Litho - I : Oxide etching

(c)

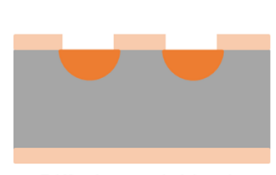

(d)

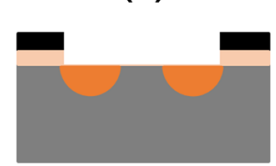

Litho - II : Oxide and

PSG etching

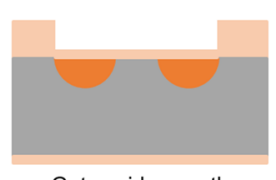

Gate oxide growth

(f)

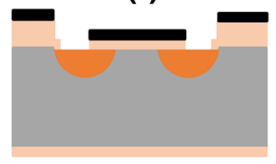

(g)

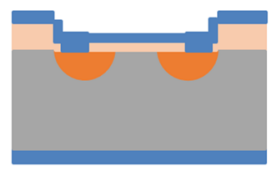

Aluminium sputtering

(h)

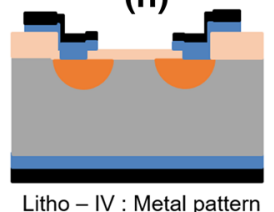

Litho - IV : Metal

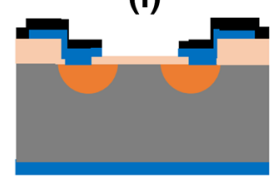

Litho - V : Lift-off

patterning

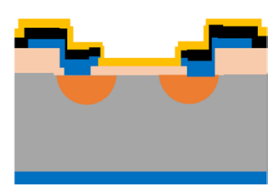

(k)

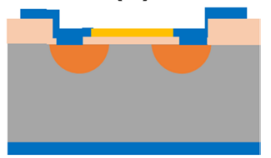

Sensing film lift-off

(I)

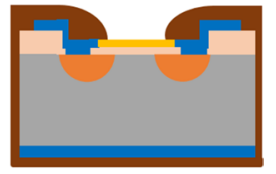

Encapsulation \& packaging

(m)
Fig. 4 Fabrication process flow of an $\mathrm{Al}_{2} \mathrm{O}_{3}$-gate ISFET pH sensor.

were patterned using photolithography, followed by etching of oxide using buffered hydrofluoric acid (BHF) (Fig. 4c). Phosphorus diffusion and the drive-in process were carried out in the source and drain regions while masking the other regions with field oxide, and a sheet resistivity of nearly
$1.74 \Omega / \square$ (Fig. 4d) was obtained. Next, after performing second-level lithography, the oxide in the gate region and backside were etched using BHF (Fig. 4e). In order to grow gate oxide, dry oxidation was carried out to obtain a $\mathrm{SiO}_{2}$ layer thickness of around $50 \mathrm{~nm}$ (Fig. 4f). Further, contact windows were patterned using third-level lithography, and the oxide was etched using BHF solution (Fig. 4g). Aluminum was further deposited using the DC sputtering process on both sides of the wafer for making electrical contacts (Fig. 4h). The aluminum was patterned using fourth-level lithography, and the metal was etched away using aluminum etchant (Transene, MA, USA) (Fig. 4i), followed by sintering in forming gas. Next, the final level of lithography was carried out to form a lift-off pattern for the sensing film (Fig. 4j). $\mathrm{Al}_{2} \mathrm{O}_{3}$ sensing film was deposited using the optimized process recipe as discussed in "Process Optimization for the Deposition of Sensing Film" (Fig. 4k), and the lift-off process was carried out to pattern the sensing film (Fig. 41). Finally, the wafer was diced, and individual devices were packaged in order to use the sensor for $\mathrm{pH}$ sensing applications.

\section{Packaging of Sensor}

The device was packaged using thick-film alumina technology. ${ }^{67}$ Graffy HYDE ${ }^{\circledR}$ software was used to make the layout design used to fabricate screen masks for the screen-printing process. The base was fabricated using screen printing on alumina substrates of size $2 \times 2$ in., where the conductor tracks and lead attachment pads were fabricated using Pd-Ag paste, followed by firing and dicing. The wire bonding pads were fabricated using Au paste, and the conductor tracks were protected using alumina substrate. The lead attachment was done using a reflow soldering process, and the devices were die-bonded using conductive adhesive compound. This was followed by the wire bonding process using 1-mildiameter $\mathrm{Au}$ wire and conductive adhesive compound, and curing was done for $10 \mathrm{~min}$ at $120^{\circ} \mathrm{C}$. Finally, an alumina cap was placed over the conductor tracks to isolate the electrical contact leads. The device was encapsulated using the dam-and-fill process, which is used to create a dam around the device using a high-viscosity potting compound, which prevents flow of epoxy into the gate area, surrounded by a low-viscosity compound ${ }^{68}$ (Fig. $4 \mathrm{~m}$ ). The curing time was experimentally optimized.

\section{Results and Discussion}

\section{Material Characterization}

The sensing film was characterized by various material characterization techniques. For XRD characterization, grazing 


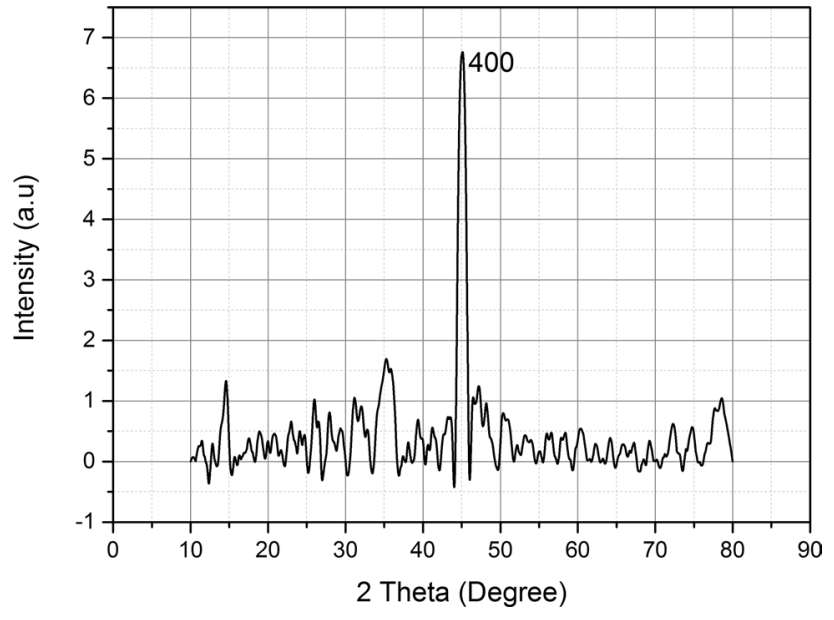

Fig. 5 XRD spectrum of $\mathrm{Al}_{2} \mathrm{O}_{3}$ thin film.

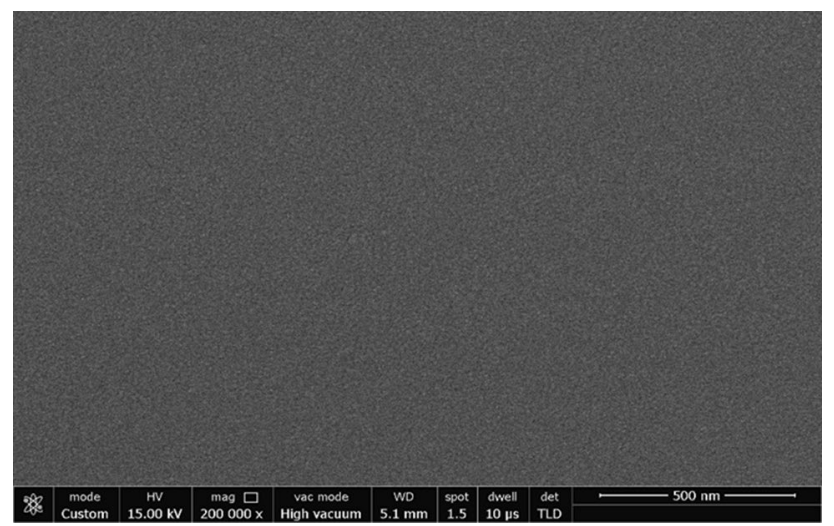

Fig. 6 FESEM image of $\mathrm{Al}_{2} \mathrm{O}_{3}$ thin film.

angle x-ray diffraction (GAXRD) was used. As shown in Fig. 5, the peak of the XRD spectrum of the sensing film was obtained at $45^{\circ}$, and the corresponding plane of the $\mathrm{Al}_{2} \mathrm{O}_{3}$ thin film was (400). ${ }^{69,70}$ The surface morphology of the sensing film was characterized using FESEM. The obtained film was uniform, as shown in Fig. 6.

EDS analysis was also carried out to determine the stoichiometry of the deposited sensing film. The elemental composition is listed in Table III which includes $\mathrm{O}_{2}, \mathrm{Al}$, and $\mathrm{Si}$ elements. Figure 7 shows the obtained EDS spectra of $\mathrm{Al}_{2} \mathrm{O}_{3}$ thin film.

XPS is a popular technique used to study the chemical composition of surfaces. Here, we analyze the oxidation state of the sensing film. The XPS spectral lines of $\mathrm{Al}_{2} \mathrm{O}_{3}$ thin film are shown in Fig. 8c. Figure 8a shows the spectrum of the $\mathrm{Al} 2 p$ energy region of the aluminum oxide. The peak is observed around $75.6 \mathrm{eV}$, which matches closely with the earlier reported data, where the binding energy of the $\mathrm{Al} 2 p$ for $\mathrm{Al}_{2} \mathrm{O}_{3}$ thin film is around $74.4 \mathrm{eV}$ to $75.8 \mathrm{eV}$. ${ }^{71-73} \mathrm{The}$

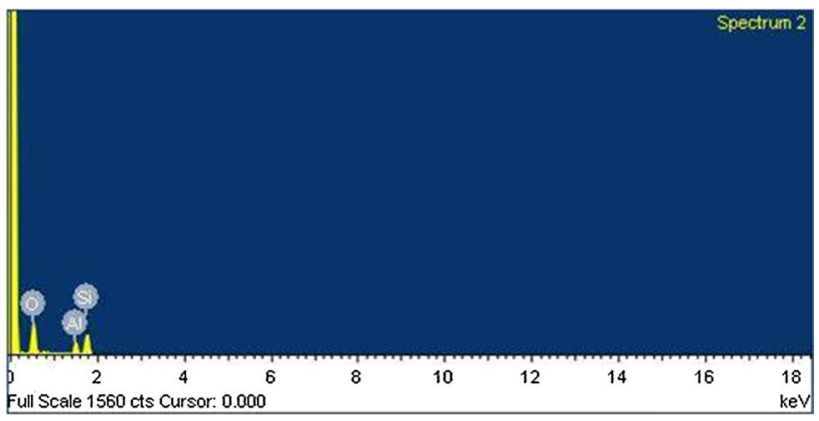

Fig. 7 EDS spectra of $\mathrm{Al}_{2} \mathrm{O}_{3}$ thin film.

Table III EDS analysis of $\mathrm{Al}_{2} \mathrm{O}_{3}$ sensing film.

\begin{tabular}{lll}
\hline Element & Weight \% & Atomic \% \\
\hline O K & 20.66 & 31.16 \\
Al K & 19.39 & 17.33 \\
Si K & 59.95 & 51.50 \\
Total & 100.00 & \\
\hline
\end{tabular}

typical XPS spectrum of the O $1 s$ is shown in Fig. 8b. Two oxygen peaks are observed using the peak deconvolution method. The deconvoluted peaks are observed at $532.3 \mathrm{eV}$ and $532.8 \mathrm{eV}$. The peak at $532.3 \mathrm{eV}$ originated from the $\mathrm{Al}-\mathrm{O}$ bond due to the adsorbed oxygen. ${ }^{71,74}$ The other peak at around $532.8 \mathrm{eV}$ originated from the $\mathrm{Al}-\mathrm{OH}$ hydroxyl group due to exposure of the film to the atmosphere (moisture) before the XPS characterization. ${ }^{75}$

\section{$\mathrm{Al}_{2} \mathrm{O}_{3}$-gate ISFET Characterization}

The packaged $\mathrm{Al}_{2} \mathrm{O}_{3}$-gate ISFET was immersed in $\mathrm{pH}$ buffer solutions (Merck) of $\mathrm{pH}$ values 4, 7, and 10 along with a $\mathrm{Ag} /$ $\mathrm{AgCl}$ reference electrode $\left(\right.$ Metrohm $\left.{ }^{\circledR}\right)$. The drain terminal was supplied a fixed voltage $(1 \mathrm{~V})$, while the source and bulk terminals were grounded. The reference voltage was swept from $-1 \mathrm{~V}$ to $+1 \mathrm{~V}$. A Keysight ${ }^{\circledR}$ B2902A source measure unit (SMU) was used for measuring the electrical characteristics of the ISFET sensor, and the electrical schematic of the test setup is shown in Fig. 9. ${ }^{17}$ We utilized a $1-\mathrm{k} \Omega$ currentlimiting resistor to prevent high current flow through the device. The obtained transfer characteristics of the device are shown in Fig. 10. We obtained a sensitivity of nearly $42.1 \mathrm{mv} / \mathrm{pH}$ using the following relationship:

Sensitivity $=\frac{\Delta V_{\text {Ref }}}{\Delta p H}$

The sensitivity was calculated at a constant current of $I_{D S}=$ $0.55 \mathrm{~mA}$ using the constant-current voltage method. ${ }^{17}$ The sensor has a nonlinear behavior over the $\mathrm{pH}$ range $4-10$. 

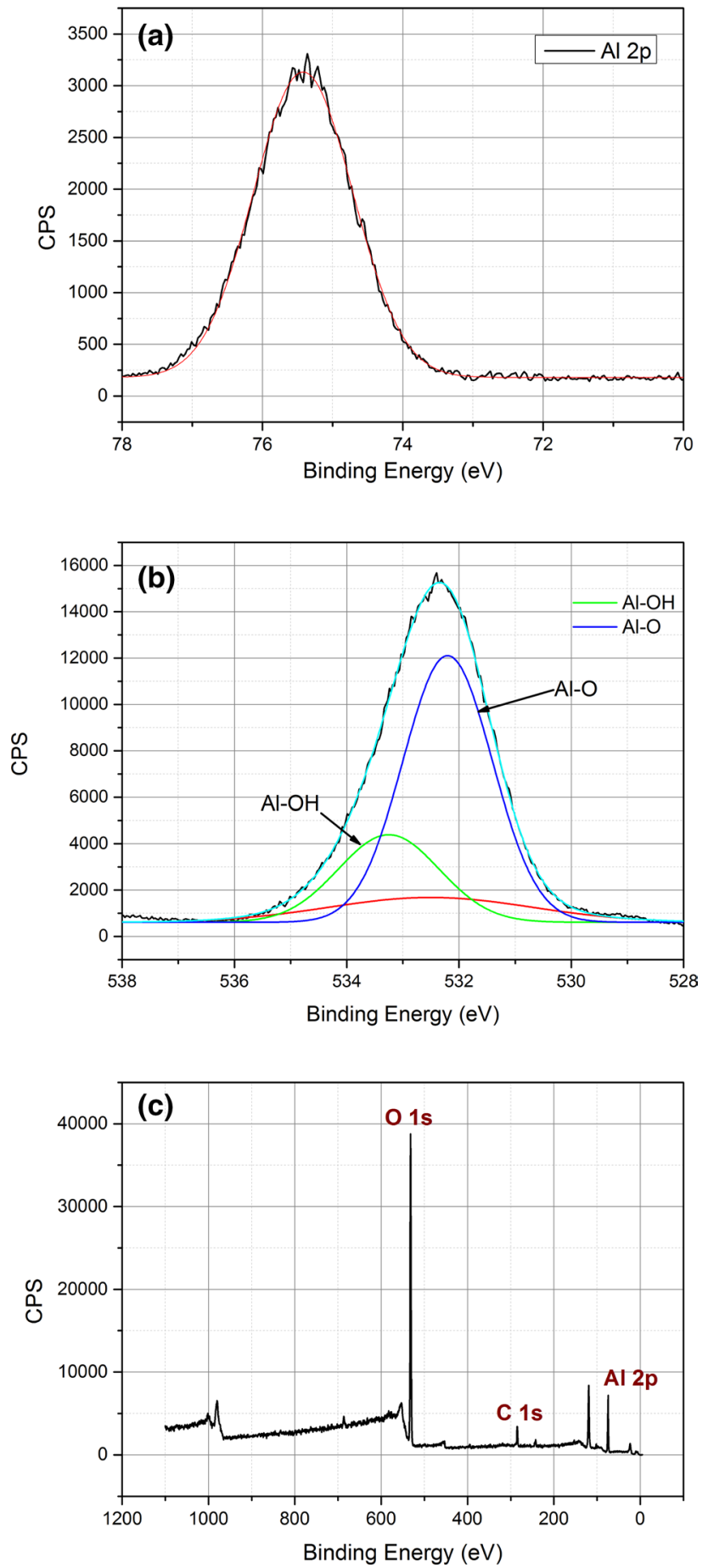

Fig. 8 XPS characterization of $\mathrm{Al}_{2} \mathrm{O}_{3}$ thin film: (a) $\mathrm{Al} 2 p$; (b) $\mathrm{O} 1 s$; (c) XPS spectra for aluminum oxide showing core levels of $\mathrm{Al} 2 p, \mathrm{C}$ $1 s$, and $\mathrm{O} 1 s$.

Figure 11 shows the output characteristics of the $\mathrm{Al}_{2} \mathrm{O}_{3}$-gate ISFET for different $\mathrm{pH}$ buffer solutions $(\mathrm{pH}=$ 4,7 , and 10). A variation in the drain current is observed for different $\mathrm{pH}$ values, indicating the dependence of channel conductance on the $\mathrm{pH}$ of buffer solutions. For a given

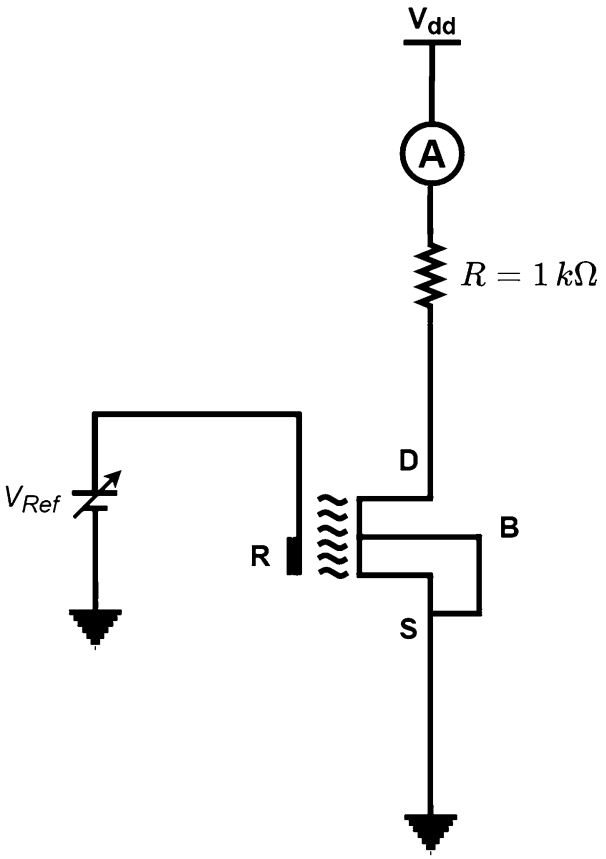

Fig. 9 Electrical schematic of test setup for ISFET $\mathrm{pH}$ sensor characterization, where $\mathrm{R}, \mathrm{D}, \mathrm{S}$, and $\mathrm{B}$ represent the reference electrode, drain, source, and bulk terminals, respectively.

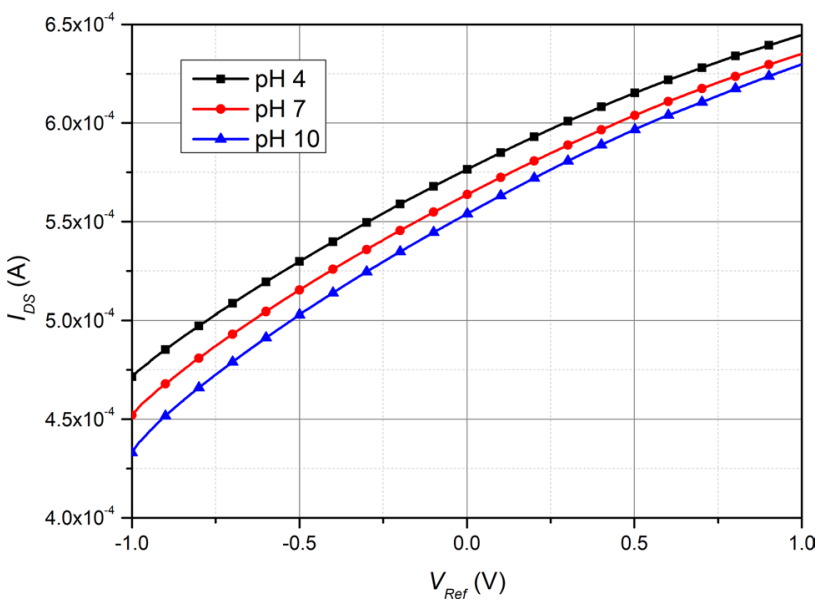

Fig. 10 Transfer characteristics of $\mathrm{Al}_{2} \mathrm{O}_{3}$-gate ISFET $\mathrm{pH}$ sensor.

$\mathrm{pH}$ buffer solution, the drain current is strongly dependent upon the applied reference voltage. Since the fabricated sensor is a depletion-mode ISFET, we obtained a considerable drain current for negatively biased $V_{R e f}$, while the current magnitude increased at higher $V_{\text {Ref }}$ due to the formation of higher inversion charge near the semiconductor-insulator interface. The drain current saturates for higher $V_{\mathrm{DS}}$ values, indicating operation of the ISFET in the saturation region. As the $\mathrm{pH}$ of buffer solutions are varied from $\mathrm{pH}=4$ (acidic) to $\mathrm{pH}=10$ (basic), we obtained a lower drain current for the corresponding $V_{\text {Ref }}$ values due to the reduction in the net 

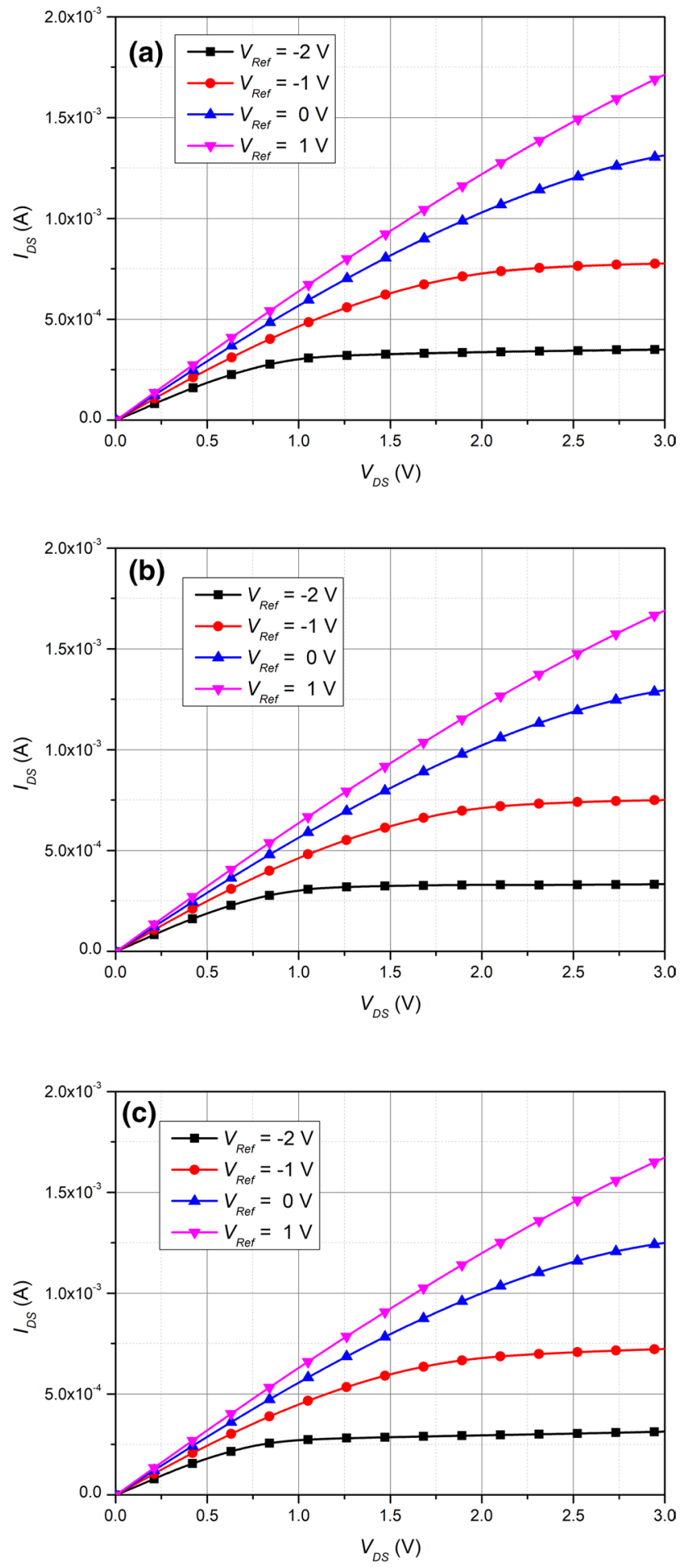

Fig. 11 Output characteristics of the $\mathrm{Al}_{2} \mathrm{O}_{3}$-gate ISFET in different pH buffer solutions: (a) $\mathrm{pH}$ 4; (b) $\mathrm{pH} 7$; (c) $\mathrm{pH} 10$.

positive charges formed at the insulator-electrolyte interface, on account of reduced $\left[\mathrm{H}^{+}\right]$ion concentration, as we move from acidic to basic solution. The charges formed at the insulator-electrolyte interface are a function of the $\mathrm{pH}$
Table IV Sensing performance comparison of $\mathrm{Al}_{2} \mathrm{O}_{3}$ thin film with other sensing films grown by sputtering techniques.

\begin{tabular}{llll}
\hline Sensing film & Deposition technique & Sensitivity & Reference \\
\hline $\mathrm{AlN}$ & $\begin{array}{l}\text { Pulsed-DC reactive sput- } \\
\text { tering }\end{array}$ & $33 \mathrm{mV} / \mathrm{pH}$ & 17 \\
$\mathrm{ZnO}$ & RF sputtering & $42.45 \mathrm{mV} / \mathrm{pH}$ & 79 \\
$\mathrm{CeO}_{2}$ & RF sputtering & $48.62 \mathrm{mV} / \mathrm{pH}$ & 80 \\
$\mathrm{ZnO}$ & RF sputtering & $31.81 \mathrm{mV} / \mathrm{pH}$ & 76 \\
$\mathrm{TiO}_{2}$ & RF sputtering & $37.73 \mathrm{mV} / \mathrm{pH}$ & 81 \\
$\mathrm{Dy}_{2} \mathrm{O}_{3}$ & Reactive sputtering & $48.6 \mathrm{mV} / \mathrm{pH}$ & 82 \\
$\mathrm{Al}_{2} \mathrm{O}_{3}$ & $\begin{array}{c}\text { Pulsed-DC reactive sput- } \\
\text { tering }\end{array}$ & $42.1 \mathrm{mV} / \mathrm{pH}$ & This work \\
& & & \\
\hline
\end{tabular}

of the solution, as described in Eq. 6, which influences the channel conductance due to the generation of surface potential as derived in Eq. 11. From Eq. 11, it can be deduced that a net positive charge in acidic solution will reduce the threshold voltage of the ISFET, as explained in Eq. 2, leading to higher drain current for acidic solutions in comparison to basic solutions.

The obtained sensor performance is better than an AlNgate ISFET, where the reported sensitivity is $33 \mathrm{mV} / \mathrm{pH},{ }^{17}$ a $\mathrm{ZnO}$ nanostructure-based $\mathrm{pH}$ sensor, which has a sensitivity of $31.81 \mathrm{mV} / \mathrm{pH}^{76}{ }^{76} \mathrm{SiO}_{2}$-gate ISFET where a sensitivity of $35 \mathrm{mV} / \mathrm{pH}$ was obtained, ${ }^{77}$ and a $\mathrm{Si}_{3} \mathrm{~N}_{4}$ sensing film-based ISFET sensor, where a sensitivity of $40.35 \mathrm{mV} / \mathrm{pH}$ was achieved. ${ }^{78}$ Table IV provides a performance comparison of $\mathrm{pH}$ sensors using sensing films grown by the sputtering process.

\section{$\mathrm{Al}_{2} \mathrm{O}_{3}$-gate ISFET Macromodeling}

The SPICE macromodel of the $\mathrm{Al}_{2} \mathrm{O}_{3}$-gate ISFET is empirically derived from the experimental results. The electrochemical parameters are swept to fit the obtained experimental results, and the optimized parameters are listed in Table V. As shown in Fig. 12, the empirical SPICE macromodel matches closely with the experimental transfer characteristics of the ISFET. The nonlinear characteristics of the sensor are attributed to the effect of various electrochemical parameters, such as surface site density and dissociation constants for surface sites, which influence the overall surface charge on the sensing film. The macromodel was simulated using HSPICE ${ }^{\circledR}$ and did not face any convergence issues.

The surface site density $\left(N_{s}\right)$, deprotonation $\left(K_{a}\right)$, and protonation $\left(K_{b}\right)$ dissociation constants are materialdependent parameters. In the past, surface site densities for different sensing films, such as $\mathrm{SiO}_{2}, \mathrm{Si}_{3} \mathrm{~N}_{4}, \mathrm{Al}_{2} \mathrm{O}_{3}$, $\mathrm{AlN}$, and $\mathrm{Ta}_{2} \mathrm{O}_{5}$ have been reported, ${ }^{17,62,83}$ where the films have been deposited using various processes, including CVD, ALD, sputtering, and thermal oxidation techniques. The characteristics of the sensing film are strongly 


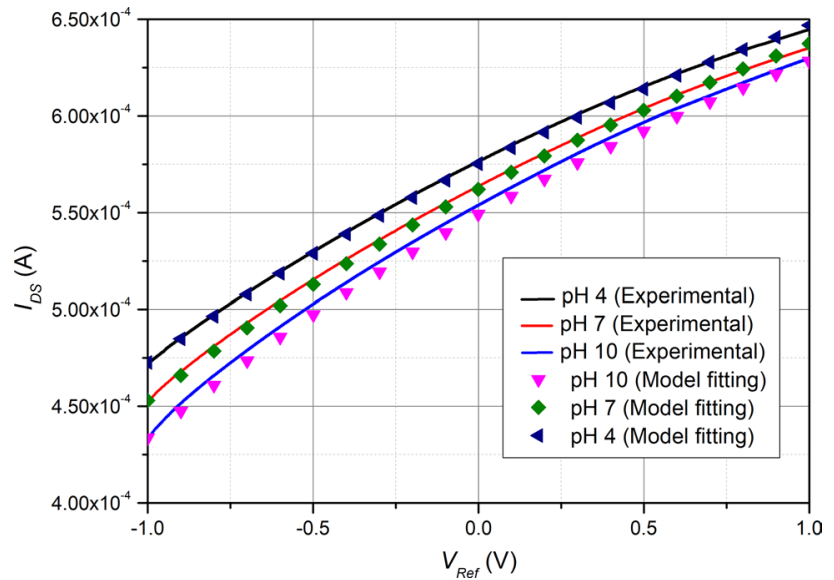

Fig. 12 Comparison of experimental results and SPICE macromodel for $\mathrm{Al}_{2} \mathrm{O}_{3}$-gate ISFET.

Table V $\mathrm{Al}_{2} \mathrm{O}_{3}$-gate ISFET electrochemical parameter values.

\begin{tabular}{ll}
\hline Parameter & Value \\
\hline$K_{a}$ & $12.6 \times 10^{-10}$ \\
$K_{b}$ & $79.9 \times 10^{-06}$ \\
$N_{s}$ & $0.4 \mathrm{E} 18 \mathrm{~m}^{-2}$ \\
\hline
\end{tabular}

dependent upon the deposition technique and process temperature, ${ }^{24,31}$ which significantly influences the material's electrochemical parameters. ${ }^{84,85}$ As discussed in "Process Optimization for the Deposition of Sensing Film," we utilized a low-temperature sputtering process for depositing $\mathrm{Al}_{2} \mathrm{O}_{3}$ sensing film, which is desirable for commercial production of sensors. We obtained the electrochemical parameters for the sensing film using a parametric sweep in order to achieve a close fit with the experimental data. The obtained silanol surface site density is higher than AlN sensing film, ${ }^{17}$ which is expected due to the higher sensitivity obtained using $\mathrm{Al}_{2} \mathrm{O}_{3}$ sensing film. ${ }^{86}$ The sensitivity of the ISFET $\mathrm{pH}$ sensor is strongly dependent upon the surface site density. ${ }^{9}$ As discussed by Van Hal et al., the higher site density leads to increased intrinsic buffer capacity $\left(\beta_{\text {int }}\right)$ of the sensing film, which reflects the ability of the sensing film to respond to the changes in $\mathrm{pH}$ values with corresponding potential changes at the insulator-electrolyte interface. ${ }^{83}$ The theoretical expression for sensitivity of the ISFET $\mathrm{pH}$ sensor is given by: $:^{9,87}$

$$
\begin{aligned}
\frac{\partial \psi_{o}}{\partial p H_{B}} & =-\frac{2.3 k T / q}{\left(2.3 k T C_{D i f f} / q^{2} \beta_{\text {int }}\right)+1} \\
& =-2.3 \frac{k T}{q} \cdot\left(\frac{1}{1+\alpha}\right)
\end{aligned}
$$

where $\alpha=\left(\frac{2.3 k T C_{\text {Diff }}}{q^{2} \beta_{\text {int }}}\right)$

Here, $\mathrm{pH}_{B}$ represents the $\mathrm{pH}$ of the solution, $k$ is the Boltzmann constant, $T$ is absolute temperature, and $q$ is the elemental charge. $\beta_{\text {int }}$ represents the intrinsic buffer capacity, which determines the capability of sensing film to rapidly respond to changes in the surface $\mathrm{pH}{ }^{88}$ The intrinsic buffer capacity is strongly dependent upon the surface site density, which is given by Eq. 15. ${ }^{9,12,89}$

$\beta_{\text {int }}=2.3 a_{H_{s}^{+}} N_{s} \frac{K_{b} a_{H_{s}^{+}}^{2}+4 K_{a} K_{b} a_{H_{s}^{+}}+K_{a} K_{b}^{2}}{\left(K_{a} K_{b}+K_{b} a_{H_{s}^{+}}+a_{H_{s}^{+}}^{2}\right)^{2}}$

The dimensionless sensitivity parameter $\alpha$ varies from 0 to 1 , depending upon the value of $\beta_{\text {int }}$ and $C_{\text {Diff }}$. The double-layer capacitance $\left(C_{\text {Diff }}\right)$ is nearly constant for different sensing films, as reported by van Hal et al., ${ }^{83}$ and thereby the magnitude of intrinsic buffer capacity $\left(\beta_{\text {int }}\right)$ plays a critical role in determining the sensitivity of the ISFET and significantly affects the surface potential $\psi_{o}$, which is responsible for the shift in threshold voltage of the sensor. In comparison to $\mathrm{SiO}_{2}$ sensing film, the reported $\beta_{\text {int }}$ of $\mathrm{Al}_{2} \mathrm{O}_{3}$ film is much higher, which is responsible for higher sensitivity of the $\mathrm{Al}_{2} \mathrm{O}_{3}$-gate ISFET $\mathrm{pH}$ sensor. ${ }^{83}$ Moreover, a small difference between the surface dissociation constants maximizes the intrinsic buffer capacity, as seen in Eq. 15, and a higher value of $\beta_{\text {int }}$ is desirable. As stated by Fung et al., the dissociation constants $K_{a}$ and $K_{b}$ for $\mathrm{Al}_{2} \mathrm{O}_{3}$ film are closer to each other in comparison to $\mathrm{SiO}_{2}$ sensing film, which aids in obtaining higher sensitivity for the $\mathrm{Al}_{2} \mathrm{O}_{3}$-gate ISFET $\mathrm{pH}$ sensor. $^{59}$

\section{Sensor Drift and Hysteresis Characterization}

Figure 13 shows the drift characteristics of the sensor in $\mathrm{pH} 4,7$, and 10 buffer solutions. In order to study the drift behavior, both the drain voltage and the reference voltage were fixed at $1 \mathrm{~V}$, while the source and bulk terminals were grounded, and the drain current was recorded using a Keysight B2902A dual-channel SMU. The measurements were recorded for $3600 \mathrm{~s}$ for each of the $\mathrm{pH}$ buffer solutions. The drift rates were calculated by dividing the total drift by the elapsed time. The accuracy of the sensor is limited by drift and hysteresis values. ${ }^{46,59}$

The primary causes for sensor drift are attributed to the slow continuous hydration of the sensing film and the transport of ionic species through the sensing film, which affects the overall insulator capacitance. ${ }^{46,56,59}$ Thus, due to the transport of ionic species through the sensing film, we obtained a chemical modification of the gate insulator. ${ }^{47}$ The transport of ionic species is explained by a trap-limited 


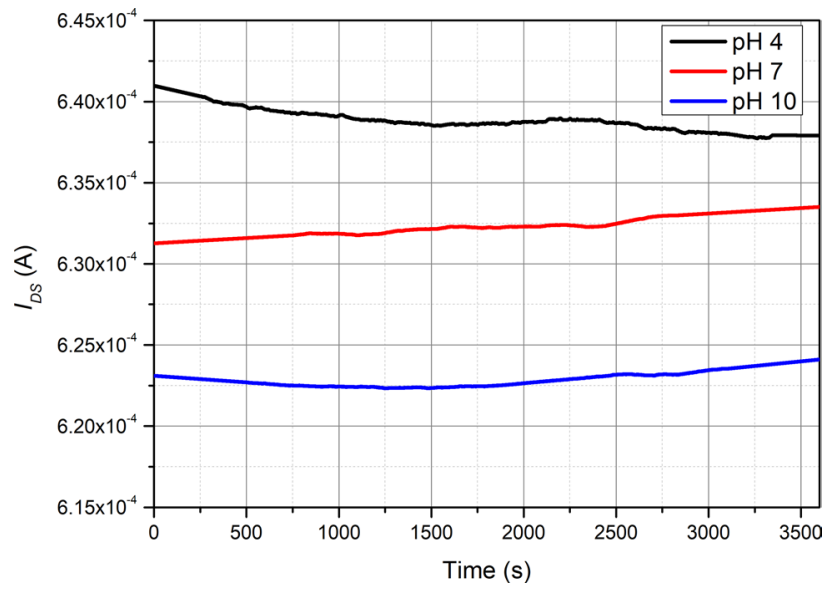

Fig. 13 Drift studies of $\mathrm{Al}_{2} \mathrm{O}_{3}$-gate ISFET for $\mathrm{pH}=4,7$, and 10 .

transport and/or hopping mechanism known as dispersive diffusion..$^{90}$ Dispersive transport is commonly observed in disordered materials, where the ion transport can arise due to trap-limited transport due to the presence of trap sites underneath the surface of the sensing film and/or hopping motion through localized states, which is reviewed in detail by Jamasb et al. ${ }^{46}$ This leads to the formation of a modified surface layer whose dielectric constant differs from the bulk insulator, where the diffusing species undergo dispersive transport across the modified surface layer formed previously in order to reach the insulator interface where further reaction occurs. Given the transport of ionic species is limited by the dispersive transport mechanism, the kinetics of growth of the modified surface layer follow a stretched-exponential time dependence in the presence of sites/traps. ${ }^{56}$ The thickness of the modified surface layer varies with time, which modifies the overall insulator capacitance. Thus, we obtained a temporal variation in the overall insulator capacitance, where a gradual reduction in the insulator capacitance causes monotonic variation in the ISFET threshold voltage, which gives rise to temporal drift in the drain current. Bousse et al. have reported that drift characteristics in $\mathrm{Al}_{2} \mathrm{O}_{3}$-gate ISFET $\mathrm{pH}$ sensors arise from bulk of the $\mathrm{Al}_{2} \mathrm{O}_{3}$ thin film and that it is not a surface phenomenon. ${ }^{45}$ Jamasb et al. have reported that the thickness of the chemically modified surface layer near the insulator-electrolyte interface is a few angstroms thick..$^{91}$ The measured drift rates for different $\mathrm{pH}$ buffer solutions of 4,7 , and 10 are 0.136 $\mu \mathrm{A} / \mathrm{min}, 0.124 \mu \mathrm{A} / \mathrm{min}$, and $0.108 \mu \mathrm{A} / \mathrm{min}$, respectively, as shown in Fig. 13. The obtained drift rates are better than TiN-gate ISFETs ${ }^{88}$ which shows high hydration resistance of $\mathrm{Al}_{2} \mathrm{O}_{3}$ sensing film, which is in agreement with Jang and Cho's study. ${ }^{92}$

Hysteresis occurs due to the interaction of the surface of the sensing film with the ions present in the solution. ${ }^{45}$ Bousse et al. have reported that the imperfections in the

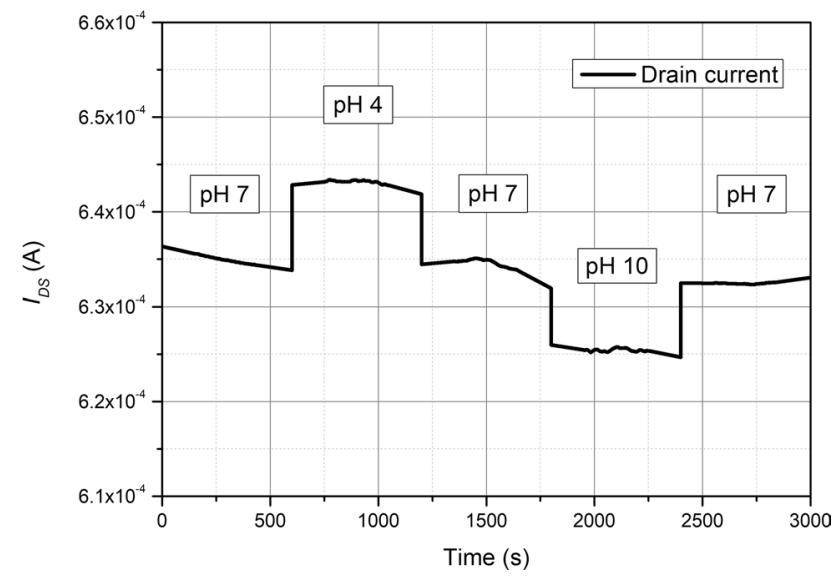

Fig. 14 Hysteresis study of $\mathrm{Al}_{2} \mathrm{O}_{3}$-gate ISFET for the $\mathrm{pH}$ cycle: $\mathrm{pH} 7$ $\rightarrow \mathrm{pH} 4 \rightarrow \mathrm{pH} 7 \rightarrow \mathrm{pH} 10 \rightarrow \mathrm{pH} 7$.

$\mathrm{Al}_{2} \mathrm{O}_{3}$ sensing film cause some degree of porosity in the film, which creates interior sites. These buried sites interact slowly with the ions in the solution, as ionic diffusion needs time to reach the buried sites underneath the insulator surface, ${ }^{93}$ causing irreversible small changes in the drain current. The imperfections in the $\mathrm{Al}_{2} \mathrm{O}_{3}$ thin film may arise due to dissolution of the sensing film in $\mathrm{pH}$ buffer solutions. ${ }^{94}$ The hysteresis study is carried out for the $\mathrm{pH}$ cycle: $\mathrm{pH} 7$ $\rightarrow \mathrm{pH} 4 \rightarrow \mathrm{pH} 7 \rightarrow \mathrm{pH} 10 \rightarrow \mathrm{pH} 7$ for a duration of 50 min. In order to carry out the measurements for hysteresis, the $V_{\text {Ref }}$ and $V_{\text {DS }}$ were fixed as $1 \mathrm{~V}$ each, and the current was recorded with a Keysight B2902A SMU. The hysteresis was measured as the change in the current from the initial to the final time duration in the $\mathrm{pH}$ cycle: $\mathrm{pH} 7 \rightarrow \mathrm{pH} 4 \rightarrow$ $\mathrm{pH} 7 \rightarrow \mathrm{pH} 10 \rightarrow \mathrm{pH}$ 7. The obtained rate of hysteresis was nearly $5.806 \mu \mathrm{A}$, as shown in Fig. 14. We also calculated the acidic and basic rate of hysteresis. The acidic and the basic hysteresis values are measured separately for the $\mathrm{pH}$ cycle $\mathrm{pH} 7 \rightarrow \mathrm{pH} 4 \rightarrow \mathrm{pH} 7$ and $\mathrm{pH} 7 \rightarrow \mathrm{pH} 10 \rightarrow \mathrm{pH}$. The measured hysteresis values for acidic and basic solutions are nearly $4.401 \mu \mathrm{A}$ and $1.405 \mu \mathrm{A}$, respectively. Therefore, the acidic and basic rate of hysteresis are obtained as $0.244 \mu \mathrm{A} /$ min and $0.078 \mu \mathrm{A} / \mathrm{min}$, respectively. The asymmetrical hysteresis of the $\mathrm{pH}$ sensor is due to the different diffusion rates of $\mathrm{H}^{+}$and $\mathrm{OH}^{-}$ions in the buried sites of the sensing film. ${ }^{95}$

\section{Conclusions}

In this work, we have reported the fabrication, characterization, and modeling of an $\mathrm{Al}_{2} \mathrm{O}_{3}$-gate ISFET $\mathrm{pH}$ sensor. The ISFET sensor was fabricated through five levels of lithography using the self-aligned process. A pulsed-DC magnetronassisted reactive sputtering process was used to deposit the sensing film, which was characterized by XRD, FESEM, 
EDS, and XPS techniques to determine the film characteristics and surface morphology. Sensor characterization was performed in different $\mathrm{pH}$ buffer solutions, and the sensitivity was found to be nearly $42.1 \mathrm{mV} / \mathrm{pH}$ in the $\mathrm{pH}$ range $4-10$. A behavioral macromodel of the sensor was built in SPICE to empirically extract various electrochemical parameters from the experimental results, and the experimental and simulated characteristics were found to be closely matching. Drift and hysteresis characteristics have also been studied, where the drift rates for different $\mathrm{pH}$ buffer solutions 4,7 , and 10 are $0.136 \mu \mathrm{A} / \mathrm{min}, 0.124 \mu \mathrm{A} / \mathrm{min}$, and $0.108 \mu \mathrm{A} / \mathrm{min}$, respectively, and a hysteresis of nearly $5.806 \mu \mathrm{A}$ has been obtained. Thus, the developed sensing film is a promising material for chemical sensors and can be adopted for other popular applications of $\mathrm{Al}_{2} \mathrm{O}_{3}$ thin film, which include electrical insulation and abrasion protection.

In summary, the main contributions of the paper are as follows:

1. Optimization of the deposition process of $\mathrm{Al}_{2} \mathrm{O}_{3}$ sensing film using cost-effective pulsed-DC magnetron-assisted reactive sputtering technique and its integration with the fabrication of ISFET-based $\mathrm{pH}$ sensor.

2. Development of a facile fabrication process for an $\mathrm{Al}_{2} \mathrm{O}_{3}$-gate ISFET $\mathrm{pH}$ sensor using five steps of lithography, where the sensing film is patterned using the liftoff process.

3. Formulation of a SPICE macromodel for the fabricated $\mathrm{Al}_{2} \mathrm{O}_{3}$-gate ISFET $\mathrm{pH}$ sensor by incorporating the electrochemical parameters, which have been empirically obtained based on the experimental data.

Acknowledgments The authors are grateful to the Director, CSIRCEERI, Pilani, for his constant support and motivation to carry out this work. They are also thankful to all the scientific and technical staff members of the Semiconductor Devices Area for their assistance in device fabrication. The authors would also like to thank MNIT, Jaipur, for providing the material characterization facility. They are grateful to CSIR, New Delhi, for providing the research facilities and financial support to carry out this research work.

Funding This study was funded by CSIR, New Delhi.

Conflict of interest The authors declare that they have no conflict of interest.

\section{References}

1. R. Edelstein, C. Tamanaha, P. Sheehan, M. Miller, D. Baselt, L. Whitman, and R. Colton, Biosens. Bioelectron. 14, 805 (2000).

2. J.-Y. Pyo, and W.-J. Cho, Semicond. Sci. Technol. 32, 035015 (2017).

3. K.S. Kim, H.-S. Lee, J.-A. Yang, M.-H. Jo, and S.K. Hahn, Nanotechnology 20, 235501 (2009).
4. H.-M. So, K. Won, Y.H. Kim, B.-K. Kim, B.H. Ryu, P.S. Na, H. Kim, and J.-O. Lee, J. Am. Chem. Soc. 127, 11906 (2005).

5. P. Bergveld, IEEE Trans. Biomed. Eng. 19, 342 (1972).

6. T.R. Martz, J.G. Connery, and K.S. Johnson, Limnol. Oceanogr. Methods 8, 172 (2010).

7. C. Jimenez-Jorquera, J. Orozco, and A. Baldi, Sensors 10, 61 (2010).

8. N. Moser, T.S. Lande, C. Toumazou, and P. Georgiou, IEEE Sens. J. 16, 6496 (2016).

9. P. Bergveld, Isfet, theory and practice, in IEEE Sensors Conference, 1 (2003).

10. P. Bergveld, Sens. Actuators B Chem. 88, 1 (2003).

11. D. Sadighbayan, M. Hasanzadeh, and E. Ghafar-Zadeh, TrAC, Trends Anal. Chem. 133, 116067 (2020).

12. M. Kaisti, Biosens. Bioelectron. 98, 437 (2017).

13. M.W. Shinwari, M.J. Deen, and D. Landheer, Microelectron. Reliab. 47, 2025 (2007).

14. M.J. Schöning, and A. Poghossian, Analyst 127, 1137 (2002).

15. G. Seo, G. Lee, M.J. Kim, S.-H. Baek, M. Choi, K.B. Ku, C.-S. Lee, S. Jun, D. Park, H.G. Kim et al., ACS Nano 14, 5135 (2020).

16. A. Poghossian, M. Jablonski, D. Molinnus, C. Wege, and M.J. Schoening, Front. Plant Sci. 11, 1792 (2020).

17. S. Sinha, R. Mukhiya, R. Sharma, P. Khanna, and V. Khanna, J. Mater. Sci. Mater. Electron. 30, 7163 (2019).

18. R. Boidin, T. Halenkovič, V. Nazabal, L. Beneš, and P. Němec, Ceram. Int. 42, 1177 (2016).

19. G. Angarita, C. Palacio, M. Trujillo, and M. Arroyave, J. Phys. Conf. Ser. 850, 012022 (2017).

20. W. Ban, S. Kwon, J. Nam, J. Yang, S. Jang, and D. Jung, Thin Solid Films 641, 47 (2017).

21. A. Korcala, P. Płóciennik, A. Zawadzka, and B. Sahraoui, Optical properties of al 2 o 3 thin film deposited by sol-gel technique, in 2015 17th International Conference on Transparent Optical Networks (ICTON), IEEE, 2015, p. 1.

22. C. Barbos, D. Blanc-Pelissier, A. Fave, C. Botella, P. Regreny, G. Grenet, E. Blanquet, A. Crisci, and M. Lemiti, Thin Solid Films 617, 108 (2016).

23. S. Jäger, B. Szyszka, J. Szczyrbowski, and G. Bräuer, Surf. Coat. Technol. 98, 1304 (1998).

24. J.D. Plummer, Silicon VLSI Technology: Fundamentals, Practice and Modeling (Pearson Education India, 2009).

25. V. Kirchhoff, T. Kopte, T. Winkler, M. Schulze, and P. Wiedemuth, Surf. Coat. Technol. 98, 828 (1998).

26. A. Belkind, Z. Zhao, D. Carter, L. Mahoney, G. McDonough, G. Roche, R. Scholl, and H. Walde, Pulsed-dc reactive sputtering of dielectrics: pulsing parameter effects, in Proceedings of the Annual Technical Conference-Society of Vacuum Coaters, 86 (2000).

27. P.J. Kelly, and R.D. Arnell, Vacuum 56, 159 (2000).

28. S. Rossnagel, Sputtering and sputter deposition, in Handbook of Thin Film Deposition Processes and Techniques, Elsevier, p. 319 (2001).

29. S. Schiller, K. Goedicke, J. Reschke, V. Kirchhoff, S. Schneider, and F. Milde, Surf. Coat. Technol. 61, 331 (1993).

30. P. Kelly, and J. Bradley, J. Optoelectron. Adv. Mater. 11, 1101 (2009).

31. J.A. Thornton, J. Vacuum Sci. Technol. A Vac. Surf. Films 4, 3059 (1986).

32. E. Tombacz, A. Dobos, M. Szekeres, H. Narres, E. Klumpp, and I. Dekany, Colloid Polym. Sci. 278, 337 (2000).

33. E.O. Filatova, and A.S. Konashuk, J. Phys. Chem. C 119, 20755 (2015).

34. C. Cibert, H. Hidalgo, C. Champeaux, P. Tristant, C. Tixier, J. Desmaison, and A. Catherinot, Thin Solid Films 516, 1290 (2008).

35. P. Katiyar, C. Jin, and R. Narayan, Acta Mater. 53, 2617 (2005). 
36. A.J. Ruys, Alumina Ceramics: Biomedical and Clinical Applications (Woodhead Publishing, 2018).

37. K. Davis, School of Doctoral Studies European Union J. (2).

38. P. Parikh, Trans. Indian Ceram. Soc. 54, 179 (1995).

39. M. Rahmati, and M. Mozafari, J. Cell. Physiol. 234, 3321 (2019).

40. L. Ferrage, G. Bertrand, P. Lenormand, D. Grossin, and B. BenNissan, J. Aust. Ceram. Soc. 53, 11 (2017).

41. J.-C. Chou, C.-Y. Weng, and H.-M. Tsai, Sens. Actuators B Chem. 81,152 (2002).

42. A.B.M. Ismail, T. Harada, T. Yoshinobu, H. Iwasaki, M.J. Schöning, and H. Lüth, Sens. Actuators B Chem. 71, 169 (2000).

43. S. Sinha, N. Sahu, R. Bhardwaj, H. Ahuja, R. Sharma, R. Mukhiya, and C. Shekhar, J. Comput. Electron. 19, 367 (2020).

44. T. Matsuo, and M. Esashi, Sens. Actuators 1, 77-96 (1981).

45. L. Bousse, H. Van Den Vlekkert, and N. De Rooij, Sens. Actuators B Chem. 2, 103 (1990)

46. S. Jamasb, S. Collins, and R.L. Smith, Sens. Actuators B Chem. 49, 146 (1998).

47. A. Elyasi, M. Fouladian, and S. Jamasb, IEEE J. Electron Devices Soc. 6, 747 (2018).

48. S.-K. Lee, W.-H. Son, Y.-S. Sohn, B.-N. Park, and S.-Y. Choi, Sens. Lett. 12(6-7), 1102-1106 (2014).

49. H.-J. Jang, M.-S. Kim, and W.-J. Cho, IEEE Electron Device Lett. 32(7), 973-975 (2011)

50. J.S. Parmar, and C. Sahu, IEEE Trans. Device Mater. Reliab. 21, 2 (2020).

51. R.W. Johnson, A. Hultqvist, and S.F. Bent, Mater. Today 17, 236 (2014).

52. R. Gordon, Atomic layer deposition for semiconductors (2014).

53. P. Bergveld, Sens. Actuators 1, 17 (1981).

54. C.-S. Lee, S. Kim, and M. Kim, Sensors 9, 7111 (2009).

55. D.-H. Kwon, B.-W. Cho, C.-S. Kim, and B.-K. Sohn, Sens. Actuators B Chem. 34, 441 (1996).

56. S. Sinha, R. Bhardwaj, N. Sahu, H. Ahuja, R. Sharma, and R. Mukhiya, Microelectron. J. 97, 104710 (2020).

57. D.E. Yates, S. Levine, and T.W. Healy, J. Chem. Soc. Faraday Trans. 1 Phys. Chem. Condens. Phases 70, 1807 (1974).

58. L. Bousse, N.F. De Rooij, and P. Bergveld, IEEE Trans. Electron Devices 30, 1263 (1983).

59. C.D. Fung, P.W. Cheung, and W.H. Ko, IEEE Trans. Electron Devices 33, 8 (1986)

60. J.A. Davis, R.O. James, and J.O. Leckie, J. Colloid Interface Sci. 63, 480 (1978).

61. M. Grattarola, G. Massobrio, and S. Martinoia, IEEE Trans. Electron Devices 39, 813 (1992).

62. S. Martinoia, and G. Massobrio, Sens. Actuators B Chem. 62, 182 (2000).

63. P. Sharma, S. Gupta, R. Singh, K. Ray, S. Kothari, S. Sinha, R. Sharma, R. Mukhiya, K. Awasthi, and M. Kumar, Int. J. Hydrogen Energy 45, 18743 (2020).

64. S. Karthikeyan, A.E. Hill, J.S. Cowpe, and R.D. Pilkington, Vacuит 85, 634 (2010).

65. J.-K. Kim, and S.-H. Jeong, J. Korean Phys. Soc. 38, 19 (2001).

66. E. Arslan, Y. Totik, and I. Efeoglu, Prog. Org. Coat. 74, 772 (2012).

67. V. Khanna, R. Mukhiya, R. Sharma, P. Khanna, S. Kumar, D. Kharbanda, P. Panchariya, and A. Kiranmayee, in Micro and Smart Devices and Systems, Springer, 2014, p. 73.

68. D. Kharbanda, and P. Khanna, in AIP Conference Proceedings, Vol. 1724, AIP Publishing LLC, p. 020034 (2016).
69. S.A. Ansari, and Q. Husain, J. Mol. Catal. B Enzym. 70, 119 (2011).

70. V. Cimalla, M. Baeumler, L. Kirste, M. Prescher, B. Christian, T. Passow, F. Benkhelifa, F. Bernhardt, G. Eichapfel, M. Himmerlich et al., Mater. Sci. Appl. 5, 628 (2014).

71. C.-S. Yang, J.-S. Kim, J.-W. Choi, M.-H. Kwon, Y.-J. Kim, J.-G. Choi, and G.-T. Kim, J. Ind. Eng. Chem. 6, 149 (2000).

72. Y.-C. Kim, H.-H. Park, J.S. Chun, and W.-J. Lee, Thin Solid Films 237, 57 (1994).

73. N. Rajopadhye, S. Dake, and S. Bhoraskar, Thin Solid Films 142, 127 (1986).

74. Y. Wu, J.T. Mayer, E. Garfunkel, and T.E. Madey, Langmuir 10, 1482 (1994).

75. R.-C. Fang, Q.-Q. Sun, P. Zhou, W. Yang, P.-F. Wang, and D.W. Zhang, Nanoscale Res. Lett. 8, 92 (2013).

76. P. Sharma, V.S. Bhati, M. Kumar, R. Sharma, R. Mukhiya, K. Awasthi, and M. Kumar, Appl. Phys. A 126, 284 (2020).

77. C. Cané, A. Götz, A. Merlos, I. Gracia, A. Errachid, P. Losantos, and E. Lora-Tamayo, Sens. Actuators B Chem. 35, 136 (1996).

78. C. Fatt, N. Bakar, N. Johari, M. Haron, N. Desa, and U. Hashim, J. Eng. Technol. (JET) 2, 23 (2011).

79. C. Haur Kao, H. Chen, M. Ling Lee, C. Chun Liu, H.-Y. Ueng, Y Cheng Chu, Y. Jie Chen, and K. Ming Chang, J. Appl. Phys. 115, 184701.

80. C.-H. Kao, C.-W. Chang, Y.T. Chen, W.M. Su, C.C. Lu, C.-Y. Lin, and H. Chen, Sci. Rep. 7, 2405 (2017).

81. J.-C. Chou, and C.-W. Chen, IEEE Sensors J. 9, 277.

82. T.-M. Pan, and C.-W. Lin, J. Phys. Chem. C 114, 17914 (2010).

83. R. Van Hal, J.C. Eijkel, and P. Bergveld, Sens. Actuators B Chem. 24(1-3), 201-205 (1995).

84. M. Ihsan, and K. Pourrezaei, J. Vac. Sci. Technol. A Vac. Surf. Films 8, 1304 (1990).

85. A.I. Pruna, N.M. Rosas-Laverde, and D. Busquets Mataix, Materials 13, 624 (2020).

86. S. Martinoia, G. Massobrio, and L. Lorenzelli, Sens. Actuators B Chem. 105, 14 (2005).

87. S. Sinha, R. Rathore, S. Sinha, R. Sharma, R. Mukhiya, and V. Khanna, in ISSS International Conference on Smart Materials, Structures and Systems (2014).

88. S. Sinha, T. Pal, D. Kumar, R. Sharma, D. Kharbanda, P. Khanna, and R. Mukhiya, Mater. Lett. 304, 130556 (2021).

89. K.B. Parizi, X. Xu, A. Pal, X. Hu, and H.P. Wong, Sci. Rep. 7, 41305 (2017).

90. H. Scher, and E.W. Montroll, Phys. Rev. B 12, 2455 (1975).

91. S. Jamasb, S.D. Collins, and R.L. Smith, in Proceedings of International Solid State Sensors and Actuators Conference (Transducers' 97), Vol. 2, 1379. IEEE (1997).

92. H.-J. Jang, and W.-J. Cho, Appl. Phys. Lett. 99, 043703 (2011).

93. L. Bousse, S. Mostarshed, B. van der Schoot, and N. De Rooij, Sens. Actuators B Chem. 17, 157 (1994).

94. R. Kummert, and W. Stumm, J. Colloid Interface Sci. 75, 373 (1980).

95. P.-C. Yao, J.-L. Chiang, and M.-C. Lee, Solid State Sci. 28, 47 (2014).

Publisher's Note Springer Nature remains neutral with regard to jurisdictional claims in published maps and institutional affiliations. 